\title{
Inquiry-Based Education: Innovation in Participatory Inquiry Paradigm
}

\author{
https://doi.org/10.3991/ijet.v15i10.11460
}

\author{
Nazirah Kamal Ruzaman ${ }^{(\varpi)}$, D’oria Islamiah Rosli \\ Tun Hussein Onn Malaysia University, Johore, Malaysia \\ annenazirah@gmail.com
}

\begin{abstract}
Inquiry-based learning is fundamental for the development of higher order thinking skills that guides learners to inquire meaningful questions that led to relevant answers, therefore awaken learners' curiosity and wonder. Recent ameliorations in technology have captivated the enthusiasm of both educators and researchers to develop inquiry-based classroom activities that emphasize the application of educational technology in the domain of school science education. Thus, we have designed a learning application "AIBASE", which assists primary school students in generating hypotheses during Science experiments. The instructional framework was used to scrutinize the effectiveness of using "AIBASE" in aiding the learning process. The results implied improvements in students' performance level. In addition, this paper also highlights the main criteria for inquiry-based learning.
\end{abstract}

Keywords-Inquiry, Digital Simulation, Participatory Design

\section{Introduction}

\subsection{Technology in education}

The brisk advancement of mobile technology offers great opportunities for students. The use of mobile technology has been proven immensely for growing further the students' engagement in teaching and learning session. Not to mention the students' motivations and learning experience itself [1]. Computer or digital simulations used in Science teaching can be defined as a computer program that mimics the behavior of a real system [2]. They can be used to investigate scientific phenomenon as a part of inquiry-based teaching.

Simulations offer a chance for learners to perform experiments by changing variables and observing the effects. Mobile technologies are literally revolutionizing school education nowadays. Mobile technologies are converting the conventional classroom setting with interactive classroom applications. For example, Frog Virtual Learning Environment (Frog VLE), 1Note and Google Classroom. With this revolution, subjects in school will be taught on virtual learning platforms through interactive lessons. Students can complete their homework and also do some revising of their studies on the gamified teaching and learning platform. 
These interactive classroom applications have the probable to enhance the students' learning experience [3]. This is because of the schemes of these mobile technologies that offer a divergent level of engagement [4]. Thus, these mobile technologies may become a trustworthy choice of technology for providing learning experiences in classroom and laboratory (within the school area), but also outside of school (home, park, etc.).

Inquiry-based education (IBL) is a form of active learning approach that is strongly student-centered that is driven by inquiry or research. Students are given a sequence of questions or task and are asked to solve and make sense of them. In inquiry-based learning, students are challenged to engage in a deep understanding of the particular courses. Effective inquiry-based learning courses are making use of purposefully structured problems or scenarios that further can develop and enhance students' critical thinking skills, interpersonal skills and group collaboration skills [5].

Science activities that use authentic inquiry-based learning involved the students in hands-on activities. They are also provided with the resources in assisting them to understand domain-specific knowledge by engaging in scientific reasoning processes; hypothesis generation, experimentation and evidence evaluation [2]. This seems to have twofold advantages; learners are able to develop understanding and knowledge about the scientific phenomena that they observe in the physical world, and they also identify how to perform the steps of scientific inquiry like scientists [6]. These two aspects are inter-related in that learners will not learn from inquiry without knowing how to do inquiry, and on the other hand, a particular domain is always required for practical inquiry skills [7].

Research on inquiry-based learning indicates that learners need support to overcome difficulties with a certain task, such as drawing a conclusion from data [8]. Support or guidance for inquiry-based learning may vary. They may including the simulation or accompanying software, the teachers, or other learning material. Thus far, many research on inquiry-based learning only focused on mobile science learning applications that follow inductive or deductive inquiry [9]. This means that the students process their idea or hypotheses to explore the observed scenario or phenomena [10]. In contrast, the abductive inquiry focused on the formation of the hypotheses of the observed phenomena [11]. An abductive inquiry was slightly investigated in the past. Only a few research have studied the advantages of using a mobile learning application in the context of inquiry-based learning, in terms of hypotheses generation.

This scenario grants us the opportunity to explore a new way to use mobile learning application through science inquiry learning activities. With this in mind, we have developed a mobile learning application, 'AIBASE', in order to explore abductive science inquiry activities. Using 'AIBASE', students can get deeper conceptual understanding in science learning, through some particular domain offered by the mobile learning application. In this particular study, the domain used is the plant ontology, specifically the photosynthesis process that occurs in plants.

Through the use of the mobile learning application 'AIBASE', students are assisted in interpreting data or hints into meaningful hypotheses. The learning process will further enhance the students' critical thinking skills and also help the students in cop- 
ing the conceptual understanding of science lessons. In order to evaluate the mobile learning application's effectiveness on students' achievements, the Triple E evaluation framework has been used [12]. The corresponding results and analyses are discussed later in this paper.

\section{Inquiry in Science}

Computer simulations can enhance traditional science instructions, such as lecturebased, textbook based, and practical work [13]. The simulation should be integrated with other classroom activities and used in a way that allows the learners to have an active role in a scientific investigation. The American National Science Education Standard recommended inquiry-based teaching and learning strategies to boost the students' curiosity and therefore build up their own scientific or conceptual understanding in science education. Therefore, this confirms the consensus in Science education that learners should be engaged in inquiry, experimentation, discovery as active agents and simultaneously develop their practices related to Science [2]. The main objective of this study is to create a form of guidance provided by teachers using particular simulation in term of innovation.

\subsection{Abductive science inquiry}

An abductive science inquiry is a form of logical inference that starts with an observation or a series of observations. The students, later on, seek to find the most likely explanation of the observations [14]. In this type of inquiry, students tend to come out with the most conceivable hypotheses, solely based on the essentials of primary theories and observations [14] with the aid of their sensory inputs and prior bits of knowledges and experiences. Then, the observation made by the students is explained using their critical thinking skills.

An abductive inquiry is so much different from the other two types of inquiry; inductive inquiry and deductive inquiry that is commonly used in science lessons. In both inductive and deductive inquiry, students are required to do the opposite of abductive inquiry, where they need to validate the data through the given hypotheses. While using the abductive inquiry, hypotheses are initially unknown. The following example using our domain of study will demonstrate the scenarios more clearly. Here is the idea related to the photosynthesis process in plants; the plants that get watered regularly are doing fine, while the unwatered plants are looking worse and drooping. In this examples, the case (hypothesis), result (observation) and rule (condition) are defined to show the differences in order.

\section{- Deduction}

○ Rule - the plants that are watered regularly are in excellent condition

- Case - the plants need water to survive/make the food

- Result - the plants need water in order to run the photosynthesis

\section{- Induction}


- Case - the plants need water to survive/make the food

- Result - the plants need water in order to run the photosynthesis

○ Rule - the plants that are watered regularly are in excellent condition

\section{- Abduction}

○ Rule - the plants that are watered regularly are in excellent condition

- Result - the plants need water in order to run the photosynthesis

- Case - the plants need water to survive/ make the food

This example shows that through both deduction and induction, a case (hypothesis) is processed with either a rule (condition) or a result (observation) in order to build another component. While for abduction inquiry, the rule and result are used together to create a case. This type of characteristic of abduction inquiry in very much suitable to inquiry or research any given problems or scenarios in science learning. This is because the students are tested to generate scientific science hypotheses that will later on lead them to a new concepts or information of the previously observed scenarios [11].

There are two crucial aspects in scientific explanations. First, they provide a unified image of how a various scientific phenomenon fit it together. Secondly, they help the students envision how things are working in the universe. Furthermore, through the literature, it is suggested that scientific explanation is a vital tool for constructing students' critical thinking skills [11]. Previous studies have demonstrated that the students are able to generate meaningful hypotheses if they are given appropriate resources. However, there is a lack of exploration of mobile learning applications through inquiry-based learning in terms of leveraging learning goals in ways they were enhancing students learning experience, especially in abductive science inquiry. Thus, a mobile web application 'AIBASE' has been designed. As a result, it allows us to evaluate technology-assisted hypothesis generation with primary school students performing abductive inquiry experiments, as described in the following sections.

\section{Mobile web Application}

In consultation with the science teachers from local primary schools, we agreed on one of the science topics (i.e. Plants; Photosynthesis process) from the Malaysia standard Science curriculum as the experimental context to test a mobile learning application that support abductive science inquiry.

\subsection{Conceptual design}

Figure 1 shows the conceptual design of the application AIBASE can be defined as a hypothetical viewpoint of the objectives that deal with the development of a mobile web application for abductive science inquiry lessons or experiment. The main reason why a mobile web learning application is developed for the classroom setting is to provide an environment that can assist students when they are performing hands-on activities or science experiments. Though a desktop computer or even a laptop can 
offer the same learning content, it is implied that the use of mobile devices can offer different learning experience through classroom activities [15].

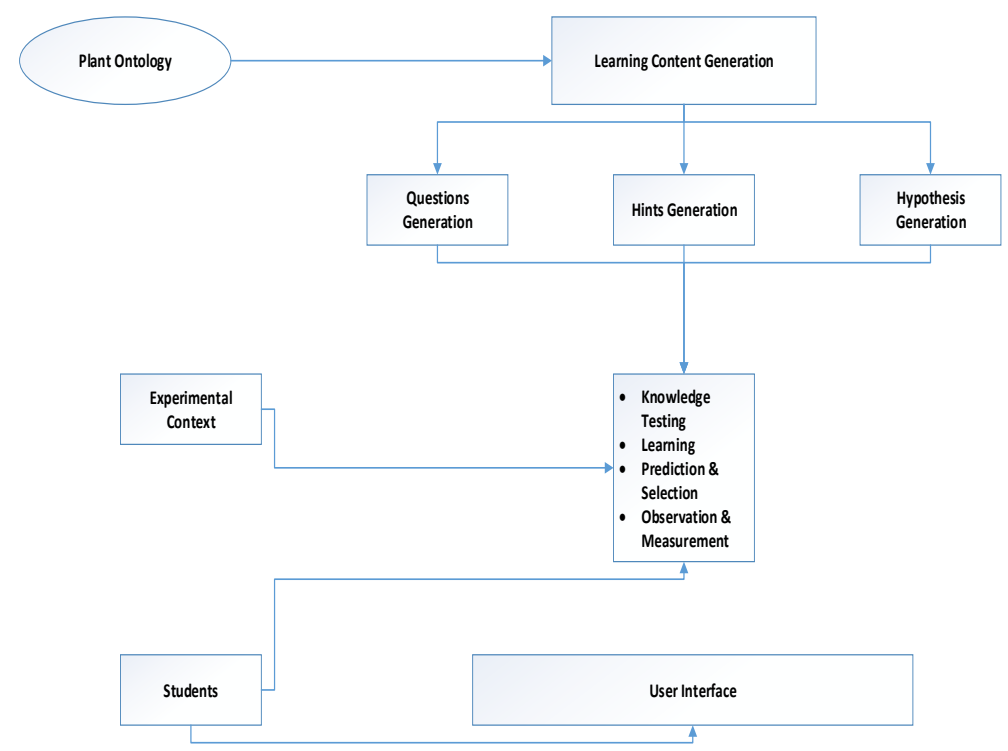

Fig. 1. Conceptual design for mobile web application

Based on this conceptual design, the four main components are defined as Knowledge Testing, Learning, Prediction \& Selection, and Observation \& Measurement. These main components are connected with a defined domain ontology via the Learning Content Generation component through learning videos and simulations, which is responsible for generating learning content in the form of varies type of Questions, suggestions or hints and hypotheses for the application.

In the given example, an ontology is defined based on one of the standard school science topics (i.e. plants). It contains all the relevant aspects of plants that includes parts of a plant, photosynthesis and characteristic of the plant. In these four components, the Knowledge Testing component is the one which is used for assessing students' knowledge by asking Questions about a given topic. The Learning component is designed for giving suggestions or hints based on the essence of the scenario (i.e. science inquiry). The Prediction \& Selection component will guide the students to generate a hypothesis after learning about the given topic. Later on, the best implies hypothesis is selected. In the Observation \& Measurement component, students can interact with the platform in order to observe and measure the scenario. Furthermore, they need to use a mobile web user interface to access the information through the application as shown in Figure 1. 


\subsection{Inquiry model}

The "AIBASE" mobile web application follows level one inquiry; exploration using Abductive Inquiry Model and the 5E's Learning Cycle Model [16]. The inquiry model consists of five phases: engagement, exploration, explanation, elaboration, and evaluation. This model may be utilized for curriculum design that gives a specific guideline to the teachers. Through this model, the students' conceptual understanding of science lesson is developed through a series of questions, hints and prior experiences.

In this particular example, the photosynthesis process is explained through a $2 \mathrm{D}$ simulation (engagement phase). The simulation will demonstrate what are the things or essential that the plants need in order to make the food or the process of photosynthesis. At the same time, students are required to run the experiment in order to prove the theory explained in the given simulation. Six small plants are required in these investigations. This experiment also takes place for a few days. The students are obligated to put one of the plants in a sealed plastic bag in direct sunlight and the other that is also in a plastic bag in a dark room. Next, place two potted plants in the sunlight and two in the dark. Then the students are required to water the bagged plants, one of the other plants in the light and one of the other plan in the dark.

Each plant is checked on for several days. The students need to consider why the plants react as they do. Figure 2 shows the screens of the mobile web application, which ask the basic questions regarding the photosynthesis process. For example, what is/are the things or essentials that the plants require in order to run the photosynthesis. The main task for students in this phase is to investigate the given phenomena by observing data (plants).

The explanation phase of this model may help the students to generate specific hypotheses for this particular investigated phenomena. In this phase, the application asks a series of questions regarding the investigation carried out during the exploration phase. This feature makes the students used their observational and critical thinking skills to answer the given questions as depicted in Figure 3. this phase guides the students towards a point where they are able to construct their own hypotheses regarding the observed data and understand the knowledge given by the mobile web application.

The main reason for not giving the answer straight away is to exploit students' critical thinking skills for fathoming the given photosynthesis concepts. In the elaboration phase, students are asked to select one of the given answers (hypotheses) regarding the given scenario (see Figure 4). in the final phase of the 5E's - evaluation, students propose a complete explanation for the given scenario after getting assistance through the use of the application. These explanations may help the students in gaining conceptual understanding of the given topic. The evaluation of the application and observation of the students' training session are both discussed in the following sections. 


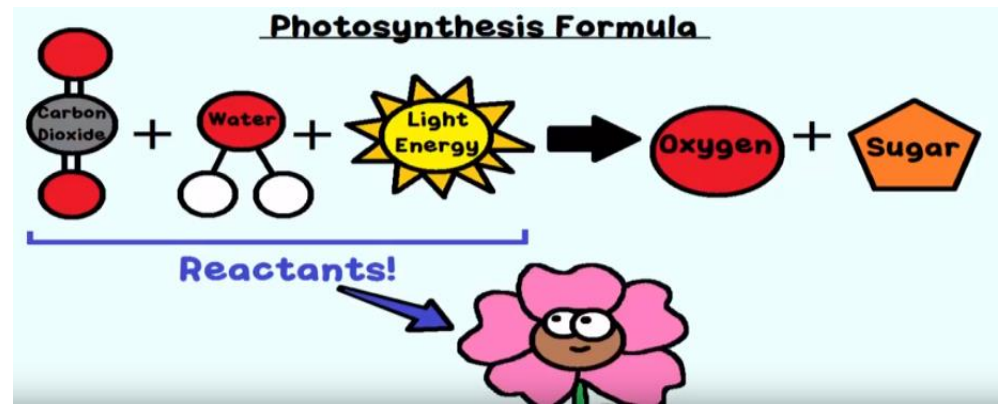

Fig. 2. Simulation of photosynthesis

"How are the plants doing? Do the plants that are getting water look the same?

Continue press ENTER

Fig. 3. Explanation phase

If you say so! Now, for photosynthesis green plants require?*

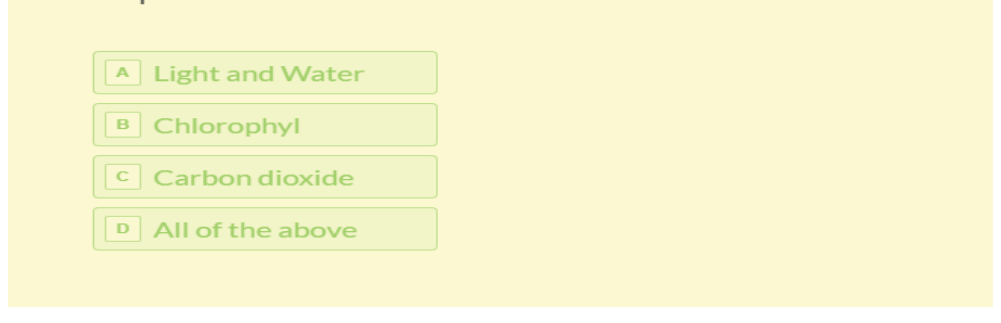

Fig. 4. Elaboration phase

The Examination Phase of this model may help students to generate scientific hypothesis for this investigated phenomena. In this phase, the application asks a series of Multiple Choice Questions regarding the gathered data. This feature makes the students use their observational and critical thinking abilities to answer the given questions. This phase of the model guides students toward a point where they are able to construct hypothesis about the observed measures and understand the knowledge presented in this application. The main reason for not giving correct answers straight away is to exploit students' critical thinking skills for comprehending the given learning concepts.

In the Selection Phase, students are asked to select one of the suggested hypothesis about the given problem. This application defines two types of the hypothesis about the underlying domain. The application extracts one of these hypothesis using random 
function. Students may get different hypothesis questions while performing the same task in classroom. In addition, the application extracts all the possible hypothesis including one correct and the other distracters by using defined ontology and its interrelated concepts.

In the final phase of the inquiry; explanation, students propose complete explanations for the given problem after getting assistance through the application. These explanations helps students to gain understanding of the topic, which can be subsequently tested by the teacher to assess learning performance during the inquiry investigation. The evaluation of the application and the learning assessment of the students are both discussed in the subsequent sections.

\section{$4 \quad$ Methodology}

In mobile learning application, evaluation can serve as a means to examine the effectiveness of the application to enable learning and offer new learning opportunities with the support of the underlying technology. For evaluation purpose, the Triple $\mathrm{E}$ evaluation framework [12] was used to assist the efforts to integrate mobile technology meaningfully into the science lesson. This framework consist of three key concepts; Engage, which examine whether the technology aid students in understanding the content; Enhance, which examine whether the technology aid students in developing more sophisticated understanding of the learning content; Extend, which examine whether the technology create the opportunities for students to learn outside of classroom.

In this study, two experiments were conducted with primary school students for evaluating the application using the Triple E evaluation framework. In the first experiment, regarded only the pilot test, both usability and mobile quality aspects being evaluated. Qualitative data were gathered about these aspects using semi-structured interview and learning observation. In this paper, only the corresponding results and analyzes of the final experiment are discussed.

In this experiment, eight students from lower primary school were selected using snowballing sampling and voluntary participated. For the invitation to participate, a procedure has been followed in which the students and their guardians needed to fill in the consent forms for the evaluation since they were all minors. This was one of the requirements of the low risks ethics notification agreed by the researcher and the parents.

In the beginning, the information regarding the experiment and the data collection process were described by researcher to the student. The students were asked to answer the quiz, filled in the questionnaires and were involved in semi-structured group discussions while answering the questions posed by the researcher.

In this evaluation process, the students were initially asked to use the application and watch the simulation of the photosynthesis process. Following this, they were asked to perform the photosynthesis experiment. Through this experiment, the students found some data essential related to each of the plants. These data helped them to understand some key concepts discussed in the given topic. At the end of the exper- 
iment, they were again asked to answer the quiz with the addition of one open-ended question related to the hypothesis. This question was used to understand how well the students engaged in the learning and critical thinking process during this abductive form of inquiry investigation.

For evaluating the usability and the utility of the application, the students were engaged in semi-structured group discussions in which students were asked to consider three questions related to their overall learning experiences about the application. The corresponding results are discussed in the following section.

\section{$5 \quad$ Result and Findings}

The Triple E evaluation framework supports the technology development process from the very early stages of the design until the final assessment of the technology in a learning context. In this study, three levels (engage, enhance, extent) of Triple E were applied to explore the use of the mobile learning application. The corresponding results and analyzes are described in the following sub-sections.

Qualitative data were gathered in semi structured group discussion and also learning observation. Three of the questions in the discussion were asked of the students for evaluating the application in term of their mobile learning experience, hypothesis generation process and comprehension about given topic. These questions were used to define the usability and the mobile quality aspects of the software quality measures.

In this group discussion, eight students participated. Most of the students considered that 'AIBASE' was easy to use and they did not find any difficulty while using the application. However two of the students found that this application is difficult to use and hard to understand in term of its guidance.

In answering the second question in the group discussion, almost all of the students were positive about their learning experiences. They were enjoyed the experience using the application. In contrast, one student disliked this application. According to them, this application was a bit boring and confusing. Despite this, most of the students enjoyed the innovative way of learning and found that the application was indeed interesting and engaging.

The responses for question three was quite promising. Most of the students felt that the given hypotheses suggestions were relevant and make them think and being reflective. These comments showed that this application presents some challenges to the students and make them reflect about the given topic. It may be argued that a certain level of challenge was maintained in this application to make it more engaging and interesting. However, some ways may be needed to convinced those students about the value for this approach.

In conclusion, the group discussion responses suggest that the application was engaging and the given suggestions make students think about the knowledge space under investigation, and it may exploit their critical thinking skills. 


\section{Discussion}

The results and analyses in this study indicate that the mobile learning environment being evaluated can help students enhancing their conceptual understanding and critical thinking skills in science. However, there are diverse results found in the literature regarding the advantages of mobile learning in classroom in terms of conceptual understanding and learning performance. In this regard, some significant work has been done in the past in which researchers found that the used of mobile learning application fostered positive attitudes towards science assessment.

According to the literature related to science learning, there are many studies stating that students equipped with mobile learning applications while performing science learning activities enhanced their knowledge compared with those who were involved in conventional ways of science learning. The results of these studies showed that students performed better in their learning activities using mobile learning environments. However, in some other studies the results showed that there was no such difference in students' learning performance with and without using a mobile learning application (Park, Parsons, \& Ryu, 2010).

Specifically to hypothesis formation activities, there are some studies found in the literature that show that students have capabilities to make scientific hypotheses and their explanations when appropriate resources are provided to them during science inquiry investigations (Oh, 2011). However, none of these studies demonstrated the perks of using mobile based learning application. Especially in terms of activities that involved hypothesis generation.

\section{Conclusion}

This study provide some insight for science teacher as to why the use of this learning application might be effective in assisting students to generate hypothesis while they were doing some experiments, hence exploiting their critical thinking skills. The main contribution of this study is the demonstration of inquiry-based learning theory using mobile learning technologies in science education for primary school students. Other than that, it can also be suggested that this learning application might be one of practical approach to enhance students' conceptual understanding of science lessons and their critical thinking skills

Although the results discussed are quite promising. There are still some limitations to this study. The achievement of students tested during this android simulation may be influenced by the students' existing knowledge of science subjects. In addition, the scope of this study only involving eight students that results in the findings of the study cannot be generalized. Research findings may differ if studies are conducted with different research population and using another subjects. Furthermore, participants only involving teachers and students. Larger sample sizes including parents may be able to provide additional data that contributes to the specifications of mobile web application in inquiry learning. The data collection process involving interviews also 
depends on what the research participants would like to share. Data interviews are limited to the perspective and experience of the participants.

\section{$8 \quad$ References}

[1] Lin, M. F., Fulford, C. P., Ho, C. P., Iyoda, R., \& Ackerman, L. K. (2012, March). Possibilities and challenges in mobile learning for K-12 teachers: a pilot retrospective survey study. In 2012 IEEE Seventh International Conference on Wireless, Mobile and Ubiquitous Technology in Education (pp. 132-136). IEEE. https://doi.org/10.1109/wmute.20 $\underline{12.31}$

[2] De Jong, T. (2006). Technological advances in inquiry learning. Science, 312(5773), 532533. https://doi.org/10.1126/science. 1127750

[3] Wu, H. K., Lee, S. W. Y., Chang, H. Y., \& Liang, J. C. (2013). Current status, opportunities and challenges of augmented reality in education. Computers \& education, 62, 41-49. https://doi.org/10.1016/j.compedu.2012.10.024

[4] Shernoff, D. J., Csikszentmihalyi, M., Schneider, B., \& Shernoff, E. S. (2014). Student engagement in high school classrooms from the perspective of flow theory. In Applications of flow in human development and education (pp. 475-494). Springer, Dordrecht. https://doi.org/10.1007/978-94-017-9094-9_24

[5] Sung, H. Y., Hwang, G. J., \& Chang, H. S. (2015). An integrated contextual and webbased issue quest approach to improving students' learning achievements, attitudes and critical thinking. Journal of Educational Technology \& Society, 18(4), 299-311. https:// doi.org/10.1109/iiai-aai.2014.82

[6] (Bell, Urhahne, Schanze, \& Ploetzner, 2010)

[7] van Joolingen, W. R., \& Zacharia, Z. C. (2009). Developments in inquiry learning. In Technology-enhanced learning (pp. 21-37). Springer, Dordrecht. https://doi.org/10.1007/ 978-1-4020-9827-7 2

[8] Alfieri, L., Brooks, P. J., Aldrich, N. J., \& Tenenbaum, H. R. (2011). Does discoverybased instruction enhance learning? Journal of educational psychology, 103(1), 1. https:// doi.org/10.1037/a0021017

[9] Santana, E. R., \& Arroio, A. (2012). The use of audiovisual approach to teach nature of science for in-service natural science teacher's education. Problems of Education in the 21st Century, 50, 90-100.

[10] Duschl, R. A., \& Grandy, R. (2013). Two views about explicitly teaching nature of science. Science \& Education, 22(9), 2109-2139. https://doi.org/10.1007/s11191-012-95 $\underline{39-4}$

[11] Oh, P. S. (2011). Characteristics of abductive inquiry in earth science: an undergraduate case study. Science Education, 95(3), 409-430. https://doi.org/10.1002/sce.20424

[12] Kolb, L. (2017). Learning first, Technology second: The educator's guide to designing authentic lesson. International Society for Technology in Education

[13] Rutten, N., Van Joolingen, W. R., \& Van der Veen, J. T. (2012). The learning effects of computer simulations in science education. Computers \& Education, 58(1), 136-153. https ://doi.org/10.1016/j.compedu.2011.07.017

[14] Råholm, M. B., Hedegaard, B. L., Löfmark, A., \& Slettebø, Å. (2010). Nursing education in Denmark, Finland, Norway and Sweden-from bachelor's degree to PhD. Journal of advanced nursing, 66(9), 2126-2137. https://doi.org/10.1111/j.1365-2648.2010.05331.x

[15] Curtis, M., Luchini, K., Bobrowsky, W., Quintana, C., \& Soloway, E. (2002, August). Handheld use in K-12: A descriptive account. In Proceedings. IEEE International Work- 
shop on Wireless and Mobile Technologies in Education (pp. 23-30). IEEE. https://doi. org/10.1109/wmte.2002.1039217

[16] Bybee, R. W. (2006). Scientific inquiry and science teaching. In Scientific inquiry and nature of science (pp. 1-14). Springer, Dordrecht.

\section{Authors}

Nazirah Kamal Ruzaman is a PhD student in Tun Hussein Onn Malaysia University. Areas of interest including inquiry-based education and application.

D'oria Islamiah Rosli is a deputy director of management and quality guarantee in Centre of Academic Development at Tun Hussein Onn Malaysia University and ICT educator.

Article submitted 2019-08-06. Resubmitted 2019-12-01. Final acceptance 2019-12-04. Final version published as submitted by the authors. 